\title{
ÍNDICE DE DIFERENÇA NORMALIZADA DA ÁGUA (NDWI) CALCULADO PARA ESTAÇÕES CHUVOSAS E SECAS NA BACIA DO CÓRREGO BARREIRO, LAGOA DA CONFUSÃO - TO
}

\author{
Wendel Barbosa Rodrigues ${ }^{(a)}$; Fernando de Morais ${ }^{(b)}$; Leticia Giuliana Paschoal ${ }^{(\mathrm{c})}$ \\ ${ }^{(a)}$ Graduando do curso de Geografia Licenciatura, Universidade Federal do Tocantins - Campus de Porto \\ Nacional, E-mail: wendel10.w0g@ gmail.com \\ ${ }^{(b)}$ Professor Doutor Associado do Curso de Geografia, Universidade Federal do Tocantins - Campus \\ Porto Nacional, E-mail: morais@ uft.edu.br \\ ${ }^{(c)}$ Pós Doutoranda em Geografia. Programa de Pós-graduação em Geografia, Universidade Federal de \\ Tocantins, Campus de Porto Nacional. E-mail: leticiagiulinapaschoal@ gmail.com
}

\section{EIXO: BACIAS HIDROGRÁFICAS E RECURSOS HIDRICOS: ANÁLISE, PLANEJAMENTO E GESTÃO}

\begin{abstract}
Resumo
Este trabalho tem como objetivo analisar as áreas com possibilidade de alagamento na bacia do córrego Barreiro. Desta forma foram selecionados os anos com maior e menor expressividade em taxa pluviométrica, dentro de um intervalo de dez anos (2007 a 2016). Dentre esses, os dados que mais se destacaram foram os dos anos de 2009, apresentando alta taxa pulviométrica, e o de 2016, com baixa pluviosidade. Imagens de satélite referentes a esses anos foram processadas e o índice de diferença normalizada da água (NDWI) foi aplicado, visando o realce dos ponto de acumulaçao hídrica nas estações chuvosa e seca, demonstrando suas diferenças e sua relação com os padrões pluviométricos. Os resultados mostraram ser possível diferenciar as área a partir do índice NDWI, sendo possíve evidencias as áreas alagadas e analisar seu comportamento.
\end{abstract}

Palavras chave: NDWI, Índice pluviométrico, Áreas alagadas, QGIS, Tocantins.

\section{Introdução}

Com a necessidade de compreender os diversos subsistemas que o compõe, diversos estudiosos se empenham para entender e explicar a dinâmica dos processos do Sistema Terra. Neste sentido, Fitz (2008, p.11) salienta que "o estudo do espaço geográfico e dos aspectos ambientais nele inseridos pressupõe uma série de conhecimentos e informações que podem ser trabalhados de maneira mais ágil, fácil e rápida com as novas tecnologias". Assim, a cartografia digital e as geotecnologias ganham destaque ao dinamizar a espacialzação de dados relacionados à temática geográfica.

Conforme Câmara et al. (2017), o geoprocessamento se caracteriza como uma "área do conhecimento que utiliza técnicas matemáticas e computacionais, fornecidas pelos Sistemas de Informação Geográfica (SIG), para tratar os processos que ocorrem no espaço geográfico". Assim, o geoprocessamento é uma tecnologia transdisciplinar, que envolve diversas disciplinas e equipamentos no seu amplo campo de atividades geotecnológicas e, difere-se também do 
sensoriamento remoto, que é a tecnologia que permite obter imagens e outros tipos de dados, da superfície terrestre, através da captação edo registro da energia refletida ou emitida pela superfície (FLORENZANO 2002). Já o SIG ou GIS (Geographic Information System) é o ambiente reponsável por processar dados georreferenciados, gráficos e não gráficos (alfanuméricos), com o objetivo de produzir análises espaciais e modelagens de superfícies (BURROUGH, 1987 apud ROSA, 2005).

Neste contexto, o presente trabalho tem como objetivo demonstrar o Índice de Diferença Normalizada da Água (NDWI, do inglês Normalized Difference Water Index) no entorno da Lagoa da Confusão, buscando averiguar a disponibilidade hídrica, num cenário intensamente modificado por conta do avanço do agronegócio. O índice NDWI permite ressaltar acumulações hídricas e minimizar o restante dos alvos da superfície, operando por meio de bandas vinculadas à esse índice. Para tanto foram utilizadas taxas pluviométricas de duas estações marcantes nessa região do estado do Tocantins, uma chuvosa e a outra seca.

Para a análise correta dos resultados do NDWI, se faz necessário enfatizar que as alterações no uso da terra, impulsionadas pelo agronegócio, acentuaram a prática da irrigação por inundação, o que pode interferir nos avanços e recuos das áreas alagadas no entorno da Lagoa da Confusão, determinando os diferentes cenários.

\section{2. Área de estudo}

Este trabalho foi realizado na região centro-oeste do estado do Tocantins, no município Lagoa da Confusão, com recorte espacial na bacia hidrográfica do córrego Barreiro, afluente do rio Urubu, situada entre as coordenadas $10^{\circ} 44^{\prime} 14^{\prime \prime}$ e $10^{\circ} 52^{\prime} 02$ " de Latitude Sul e, 49 33'02" e 49 39' 41" de Longitude Oeste (Figura 1). A área em análise possui aproximadamente 68,9 $\mathrm{km}^{2}$, com clima caracterizado segundo o método de Thornthwaite, como B1wA'a' - clima úmido com moderada deficiência hídrica no inverno. Apresenta pluviosidade com variação média anual entre 1.400 e $1.700 \mathrm{~mm}$, distribuindo-se no verão em torno de 390 e $480 \mathrm{~mm}$ ao longo de três meses consecutivos,com temperaturas mais elevadas nos meses de agosto e setembro. Os solos predominantes são os Plintossolos e Gleissolos (SEPLAN, 2008). 


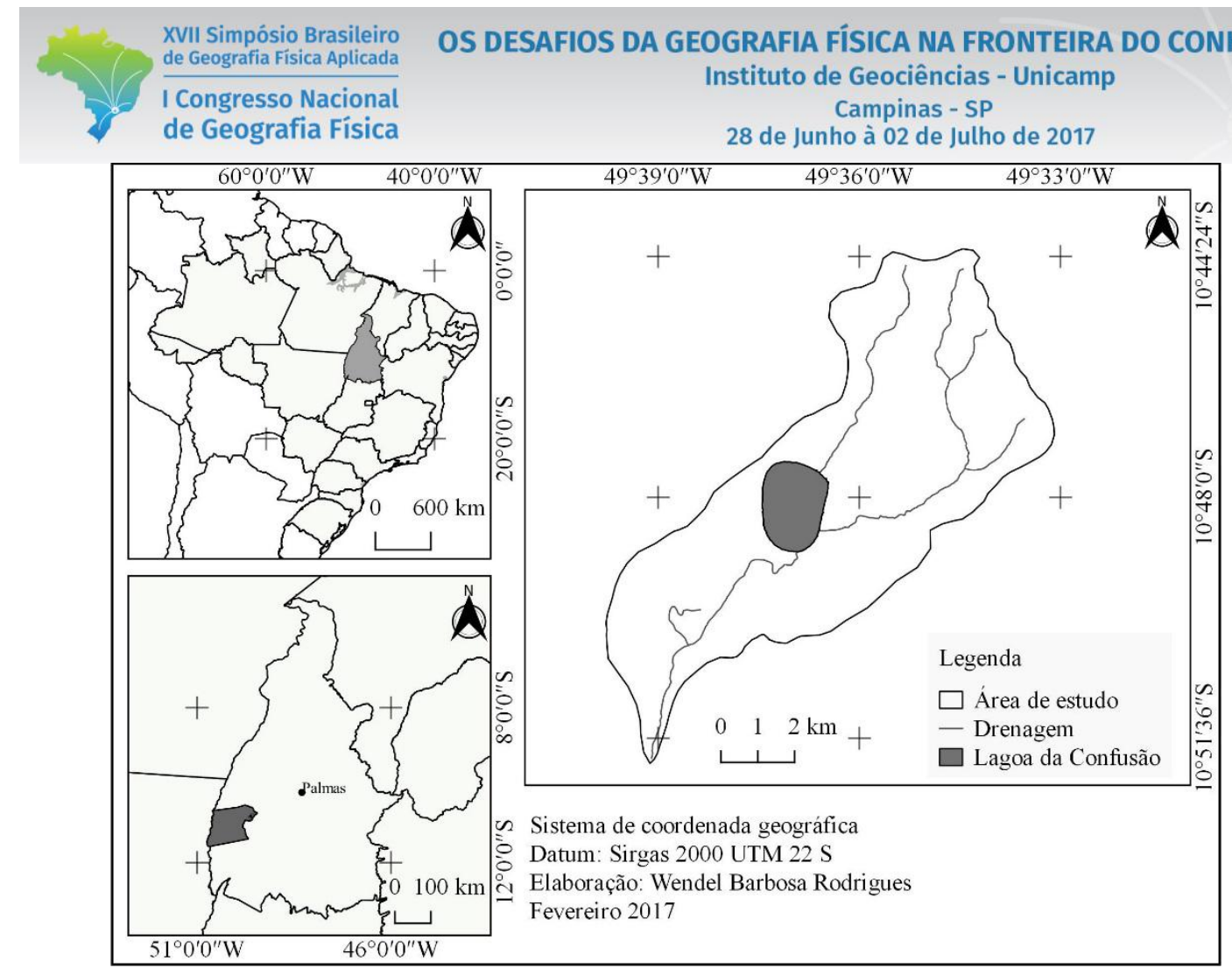

Figura 1 - Mapa de localização da área de estudo.

\section{Materiais e metodologia}

A obtenção dos dados ocorreu por meio do acesso a imagens de satélites e aos dados pluviométricos da área. As imagens foram adquiridas no site EarthExplore, que disponibiliza gratuitamente produtos dos satélites Landsat 5, sensor TM e Landsat 8, sensor OLI. O uso dos dois satélites fez-se necessário para abranger imagens inseridas em um intervalo temporal de 10 anos, com início no ano de 2007 até o ano de 2016, do qual se escolheram dois anos mais representativos referentes ao potencial pluviométrico, destacando-se o ano de 2009 e 2016. Deste modo às imagens obtidas e trabalhadas são das datas de13/05/2009;02/09/2009;14/04/2016 e 05/09/2016, com resolução espacial de 30m, órbita 223 , ponto 67. Baixadas nas estações, chuvosa (janeiro, fevereiro, março, abril e maio) e seca (agosto, setembro e outubro).Os anos de 2012 e 2013 apresentam ausência de dados, tendo sido excluídos das observações.

Os dados pluviométricos foram obtidos no site do Instituto Nacional de Meteorologia (INMET) através do Banco de Dados Meteorológicos históricos. Como não foi possível obter a taxa pluviométrica do município de Lagoa da Confusão (por não possuir estação meteorológica), os dados foram adquiridos na estação convencional de Porto Nacional (TO), permitindo acesso à pluviosidade de cada mês no intervalo desses 10 anos. Depois da análise desses dados, selecionaram-se os anos que apresentaram maior e menor quantidade de chuva. 
O modelo para obtenção do índice NDWI foi aplicado aos anos de 2009 e 2016, por apresentarem alta e baixa taxa pluviométrica, respectivamente. O processamento das imagens foi realizado no software QGIS versão 2.18.2, utilizando-se do sistema de coordenadas UTM com Datum SIRGAS 2000, Zona 22 Sul. No ambiente SIG foi realizado acorreção atmosférica das bandas, pelo complemento Semi-AutomaticClassificationPlugin (SCP), melhorando a qualidade destas, sendo ainda feitas as combinações das bandas, visando o realce de superfícies com acumulações hídricas.

As imagens do satélite Landsat 5 abrangeram as estações chuvosa e seca de 2009, usando-se a banda 2 (verde) e banda 4 (infravermelho próximo), já Landsat 8 as imagens das estações chuvosa e seca do ano de 2016, utilizando-se as bandas 3 (verde) e banda 5 (infravermelho próximo). Desse modo, usou-se o parâmetro proposto por McFeeters (1996), onde os valores de NDWI variam entre -1 e 1 . Assim, para NDWI $\geq 0$ tem-se áreas com presença de água e para NDWI $\leq 0$ não ocorre a presença de água na superfície do terreno (PEREIRA e MORAIS, 2015).

O resultado do índice de diferença normalizada da água (NDWI) foi obtido através do cruzamento das bandas, procedimento semelhante ao NDVI. Embora as imagens sejam produtos de satélites diferentes, a fórmula da equação utilizada foi a mesma, alterando-se apenas seus elementos, ou seja, na aplicação da fórmula, altera-se apenas as bandas na equação 1 (Landsat 5) e 2 (Landsat 8):

$$
\begin{aligned}
& \text { NDWI }(\text { Landsat } 5)=(\mathrm{b} 2-\mathrm{b} 4) /(\mathrm{b} 2+\mathrm{b} 4) \\
& \text { NDWI }(\text { Landsat8) }=(\mathrm{b} 3-\mathrm{b} 5) /(\mathrm{b} 3+\mathrm{b} 5) \quad \text { (Equação 2) }
\end{aligned}
$$

Com base nesse procedimento chegou-se aos valores do índice de diferença normalizada da água nos períodos pré-determinados. Os dados numéricos foram realçados com atribuição de falsa cor, composições coloridas que destacam os objetos de observação, e com a utilização de outras ferramentas para melhorar a análise dos dados em questão.

\section{Resultados e Discussão}

De acordo com Pereira e Morais (2015), a baixa variação topográfica e características de relevo, predominantemente plano ou com suave ondulado na planície aluvial, aliada às propriedades dos solos, contribuem categoricamente para elevação do lençol freático e inundação das planícies nessa região (Figura2). A aplicação do NDWI teve a finalidade de demonstrar as feições nas quais podem se encontrar o acúmulo de corpos hídricos, permitindo a verificação e analise da dinâmica das áreas alagadas, relacionando com os dados pluviométricos é possível notar o comportamento do lençol freático no entorno da Lagoa da Confusão. 


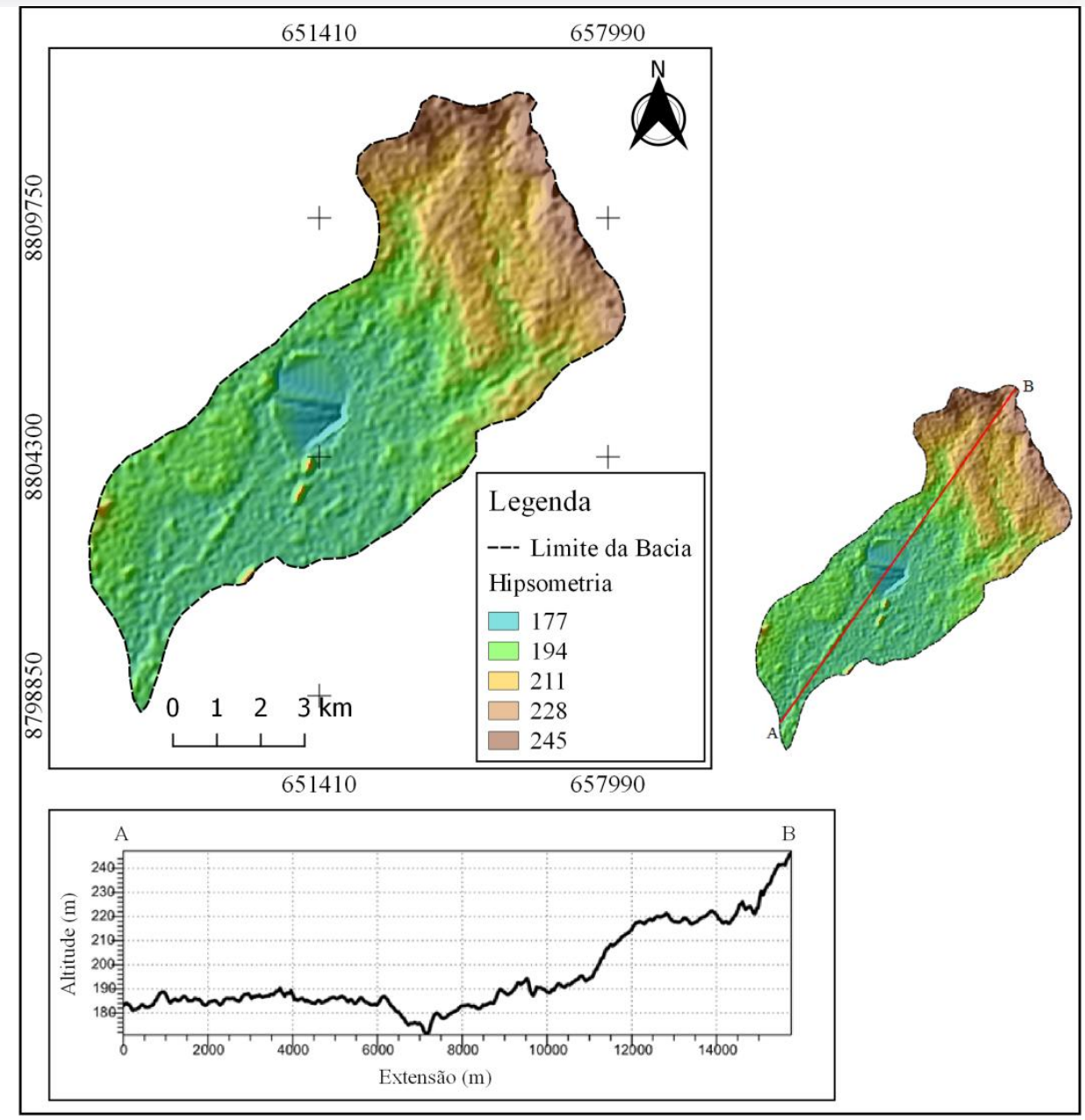

Figura 2: Mapa hipsométrico, com perfil topográfico A - B.

Com base nos dados da estação convencional de Porto Nacional, disponibilizados pelo INMET, torna-se evidente o agravamento da disponibilidade hídrica desta região, desde 2009. O ano de 2016 apresenta registros de baixos índices de pluviosidade, tanto na estação chuvosa como na seca, conforme verificado nos gráficos da figura 3. 


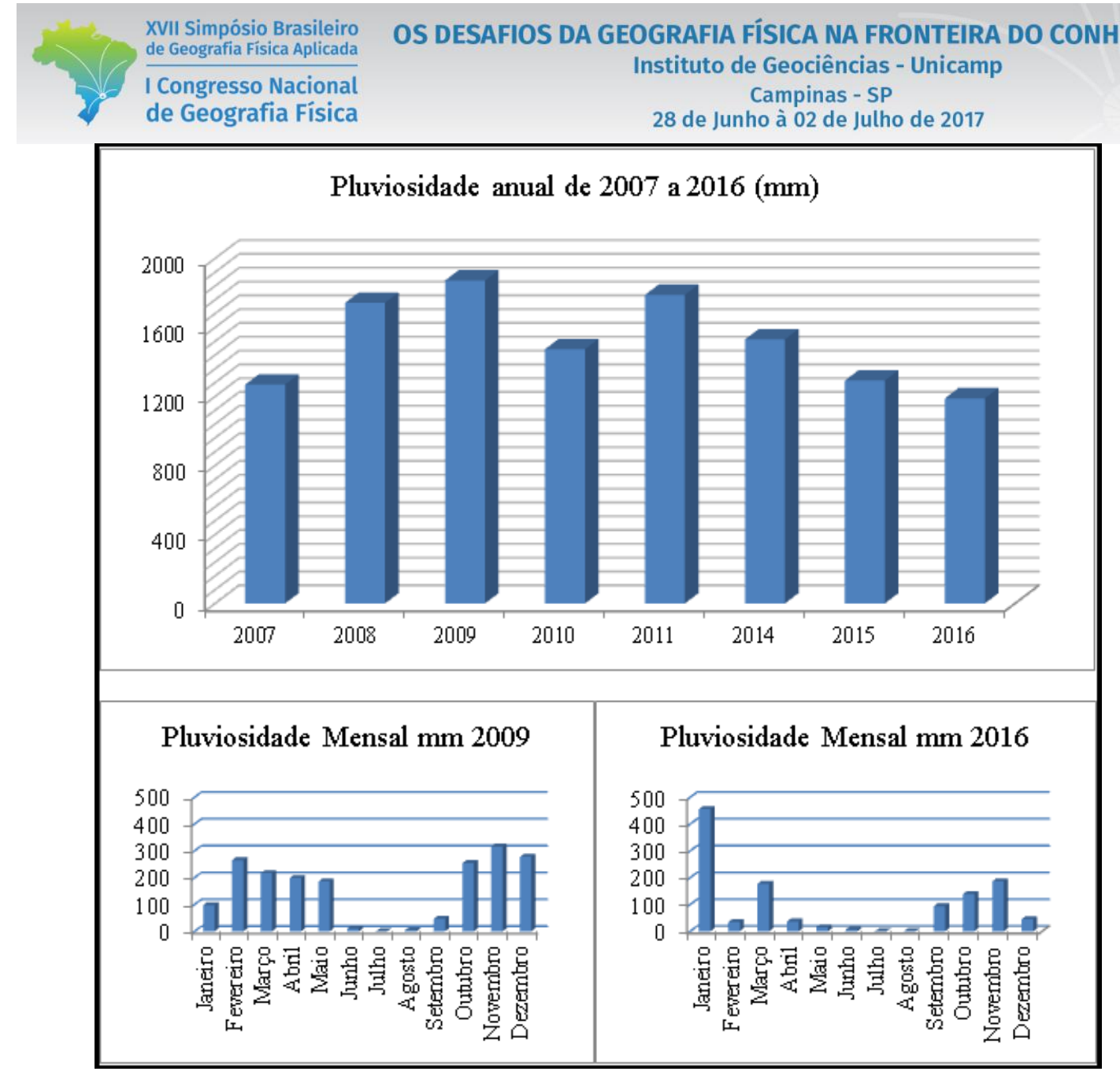

Figura 3 - Dados pluviométricos anuais, entre o período de 2007 a 2016, e pluviosidade mensal dos anos de maior (2009) e menor taxa pluviométrica (2016).

Com base na análise das taxas de precipitação total dos anos de 2009 e 2016 , foram aplicados os processamentos de dados referentes ao NDWI. Com o resultado de cada ano e estação, pode-se fazer a análise de que na estação chuvosa de 2009 há uma concentração de áreas úmidas nas partes baixas topograficamente, no entorno Lagoa da Confusão e no sentido sudoeste da bacia, sendo que essas áreas, onde ocorre à concentração de solos argilosos e áreas pantanosas, possuem valores positivos.

Na estação seca de 2009, diante das práticas de irrigação por inundação, o nível do lençol freático é alterado, o que faz com que a maior parte desta área apresente valores intermediários, na faixa de $0.012 \mathrm{a}-0.421$ no intervalo de abrangência do NDWI. A maior representatividade de valores negativos, tanto na estação chuvosa como na seca, está localizado nas áreas de maior altimetria, que apresentam a ocorrência de crosta laterítica, no sentido nordeste da lagoa, características demonstradas na figura 4A e B (referentes às estações chuvosa e seca de 2009).

No ano de 2016 tanto na estação chuvosa como na seca apresentam na maior parte da área bacia valores negativos, na faixa de -0.637 a -0.854 . Devido à baixa quantidade chuva neste 
período, percebe-se que mesmo nas áreas no entorno da bacia não mantiveram os valores positivos, registrando regressos nas porções alagadas da lagoa, como podemos ver na figura 4C e D referem-se às estações chuvosas e secas de 2016, respectivamente.

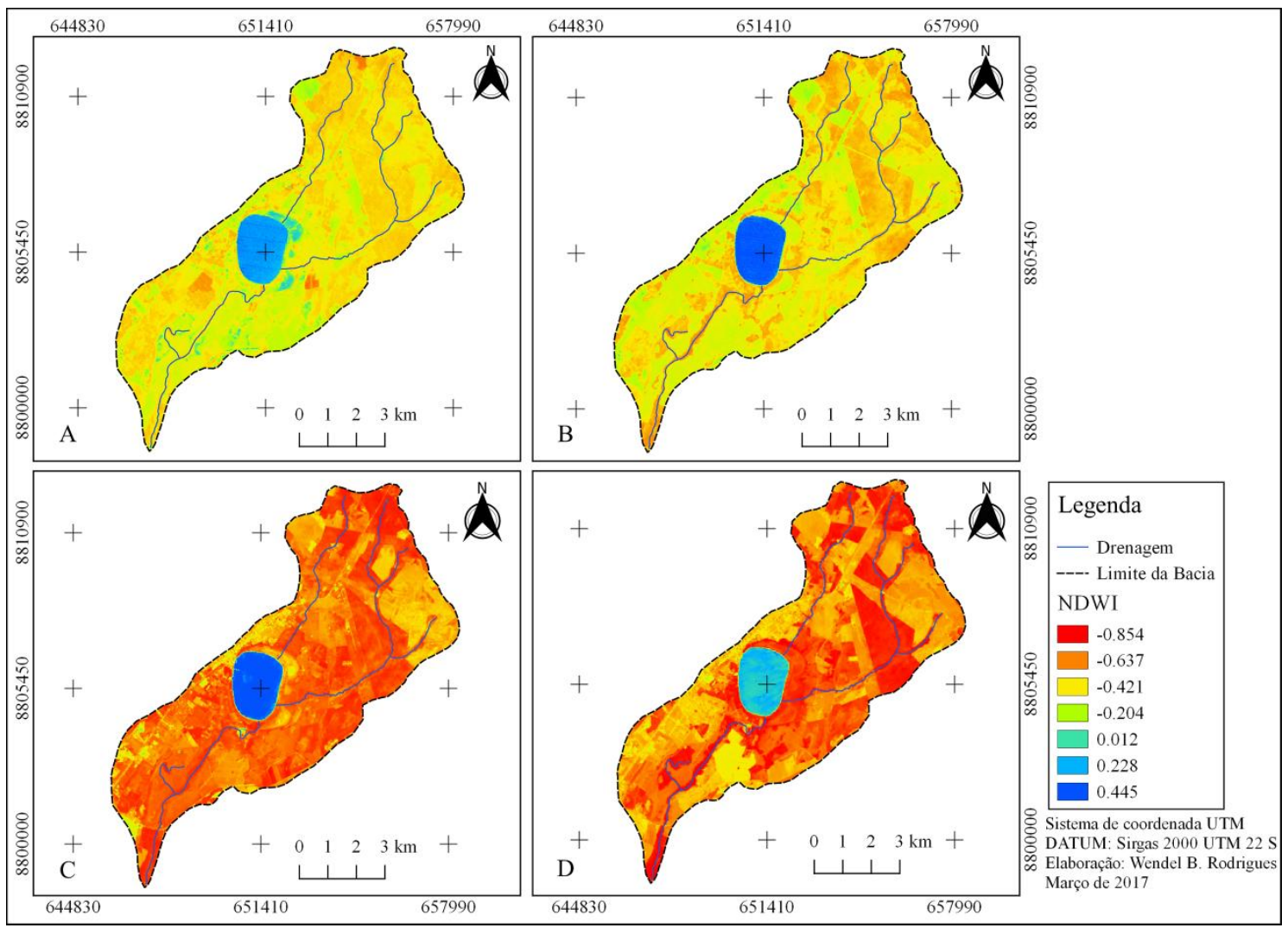

Figura 4 - Distribuição do índice NDWI gerado para área estudada. A e B, C e D, referem-se às estações chuvosa e seca do ano de 2009 e 2016, respectivamente.

É importante salientar que no período analisado, ocorreram modificações do uso da terra, com práticas de irrigação por inundação, entre outras alterações na fisiologia da paisagem, que influenciam nos avanços e recuos das áreas alagadas no entorno da Lagoa da Confusão e, consequentemente, nos resultados de NDWI.Nota-se que nestes anos, na estação chuvosa de 2009 há uma expansão das áreas alagadas, caso contrário acontece na estação seca, na qual ocorre uma regressão dessas áreas. O ano de 2016 demostrou um grande recuo nas áreas alagadas, principalmente na estação seca, registrando uma redução do entorno da Lagoa da Confusão de $221.024 \mathrm{~m}^{2}$ (Figura 4). 


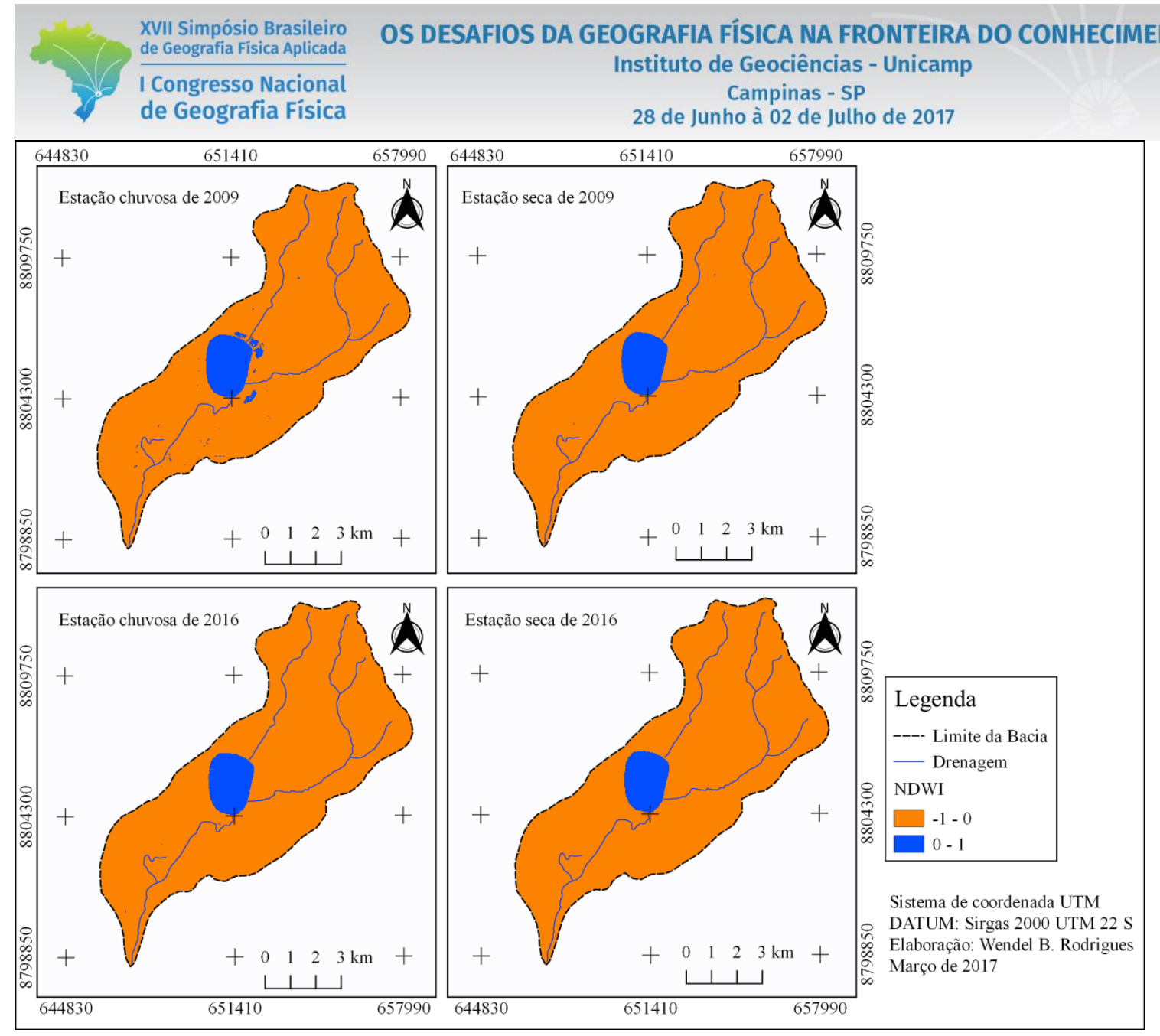

Figura 5 - Áreas alagadas das estações chuvosa e seca dos anos de 2009 e 2016.

Através dos cálculos do NDWI aplicado ao perímetro da Lagoa da Confusão, que equivale aproximadamente $3.545 .624 \mathrm{~m}^{2}$, foi possível obter resultados de avanços e recuos das áreas alagadas, sobretudo, na borda da lagoa nos sentidos nordeste e sudoeste. Na estação chuvosa de 2009, obteve-se um avanço de 11,5\% nas áreas alagadas, já na estação seca houve um recuo de 1,4\%. Em 2016 na estação chuvosa, diferentemente do comportamento dos corpos hídricos deste mesmo período em 2009, há um recuo de 3,3\%, enquanto que para a estação seca houve umaconsiderávelregressãode $6,2 \%$ das áreas alagadas.

\section{Considerações Finais}

A aplicação do índice de diferença normalizada da água (NDWI) apresentou resultados satisfatórios, de modo que, tornou-se possível a espacialização das áreas alagadas, apresentando os seus devidos avanços e recuos em cada ano, com sua dinamicidade vinculada ao relevo, propriedades especificas do solo, uso da terra e das condições climáticas da área.

Com isso, a elaboração do modelo NDWI mostra-se como uma ferramenta eficaz para o mapeamento das áreas úmidas e propícias a alagamento. A distribuição das áreas alagadas 


\section{OS DESAFIOS DA GEOGRAFIA FÍSICA NA FRONTEIRA DO CONHECIMENTO \\ Instituto de Geociências - Unicamp \\ Campinas - SP \\ 28 de Junho à 02 de Julho de 2017}

variou conforme o ano e as estações, chegando aos níveis mais baixos na estação seca em 2016.

A análise dos dados levanta um questionamento referente à causa do recuo das áreas alagadas nesse ano, além das alterações causadas por mudanças no uso da terra: apesar da média de pluviosidade razoavelmente elevada no intervalo de tempo entre 2007 e 2016, o índice pluviométrico registrado decresce a partir de 2009 e esse quadro se agrava entre os anos de 2015 e 2016.

Estudos mais detalhados poderiam esclarecer as causas deste comportamento, podendo ainda apontar a influência de fenômenos climáticos globais, como El niño, no prolongamento do período de estiagem e consequente agravamento na disponibilidade hídrica da área.

\section{Agradecimentos}

A presente pesquisa foi desenvolvida com auxílio financeiro da Fundação de Amparo à Pesquisa do Estado do Tocantins, através do Programa de Pesquisa em Recursos Hídricos, processo $n^{\circ}$ 2014.20300.000009. O estudo foi também financiado pelo Conselho Nacional de Desenvolvimento Científico e Tecnológico - CNPq através do Edital Universal, processo $\mathrm{n}^{\circ}$ 485433/2013-3.

\section{Referências Bibliográficas}

FITZ, P. R. Geoprocessamento sem complicação, Oficina de textos, São Paulo, 2008.

CÂMARA, G., MONTEIRO, A. M., DAVIS, C. Geoprocessamento: teoria e aplicações. S. J. Campos: INPE, 2001. Disponível em: <www.dpi.inpe.br/gilberto/livro>. Acessado em: 10 de jan. 2017.

Rosa, R. Geotecnologias na geografia aplicada,Revista do Departamento de Geografia, 16 (2005) 8190.

Secretaria de Planejamento e Meio Ambiente. Diretoria de Zoneamento Ecológico-Econômico. Atlas do Tocantins: subsídios ao planejamento da gestão territorial. Palmas: SEPLAN, 2008.

Florenzano, T. G. Iniciação em sensoriamento remoto, Oficinas de textos, São Paulo, 2007.

Brasil, Instituto Brasileiro de Geografia e Estatística (IBGE). Cidades. Disponível em: $<$ http://cidades.ibge.gov.br/xtras/perfil.php?codmun=171190>. Acesso em: 05 de Fev. 2017.

PEREIRA, G. C., MORAIS, F. de, Índice NDWI e imagem SRTM aplicados ao mapeamento das áreas inundáveis do entorno da Lagoa da Confusão - TO,In:Territórios brasileiros: dinâmica, potencialidade e vulnerabilidades, p. 511 a 518, Teresina - Piauí, 28 junho a 4 de julho de 2015.

Instituto Nacional de Metereologia (INMET),http://www.inmet.gov.br/portal/

Brenner, V. C., Guasselli, L. A. Índice de diferença normalizada da água (NDWI) para identificação de meandros ativos no leito do canal do rio Gravataí/RS - Brasil.In: ANAIS XVII SIMPÓSIO BRASILEIRO DE SENSORIAMENTO REMOTO - SBSR, João Pessoa-PB, Brasil, 25 a 29 de abril de 2015, INPE.

Marth, J. D., Moura, N. S. V., Koester, E. Localização e mapeamento de Áreas Úmidas na Sub-bacia Hidrográfica Arroio Santa Isabel, através do Método NDW, Geografia (Londrina) v. 25. n. 1. p.23-41, jan/jun, 2016. 
Pereira, G. C. Contribuições à Geomorfologia da Lagoa da Confusão - TO. 2016. 125 f. Dissertação (Mestrado em Geografia) Programa de Pós-Graduação em Geografia, Universidade Federal do Tocantins - UFT, Porto Nacional, TO. 